\title{
COMENTARIO
}

\section{Ángel Palerm y el trabajo de campo: un legado que perdura}

\author{
Gustavo Lins Ribeiro \\ $y$ Robert $V$. Kemper (in memoriam)
}

$\mathrm{M}$ éxico ha sido el hogar de algunos de los antropólogos más brillantes del mundo durante décadas. A través de los artículos presentados en este número de Desacatos tenemos la oportunidad de escuchar a varios autores describir la importancia del trabajo de campo en la carrera de uno de los antropólogos más prominentes de este país: Ángel Palerm. Junto a Margarita Nolasco, Arturo Warman y Guillermo Bonfil Batalla - todos fallecidos-, Palerm fue un actor central en la creación de algunos de los nuevos centros de formación e investigación antropológica más importantes de México, como los departamentos de Antropología de la Universidad Iberoamericana (UIA) y de la Universidad Autónoma Metropolitana-Iztapalapa (UAM-I), así como el Centro de Investigaciones y Estudios Superiores en Antropología Social (CIESAS). Con su esfuerzo, Palerm y sus colegas de la década de 1960 delinearon la antropología mexicana contemporánea. Escritor prolífico, Ángel Palerm publicó varios trabajos seminales en aspectos teóricos y otros basados en investigación empírica. Pero aquí nos enfocaremos en su legado para la enseñanza y la definición del trabajo de campo. Como vemos en los artículos conjuntados, el alcance de su trabajo no se limita a México, sino que podemos encontrarlo en otros países, incluyendo Estados Unidos y España. Aun más, al discutir el trabajo de Palerm constatamos que la tradición mexicana de trabajo de campo bien puede contribuir a mejorar otras antropologías del mundo.

Sin embargo, esta tradición mexicana no surgió de la nada, como demuestra Marisol Pérez Lizaur en su artículo. Ella llega hasta Boas con tal de reconstruir las experiencias e interrelaciones que influyeron en la visión de Palerm, en especial su profesora Isabel Kelly, quien fuera alumna de Kroeber. El texto de Pérez Lizaur revela otras conexiones, como las que Palerm tuvo con Julian Steward y Eric Wolf. Su análisis pone de manifiesto que los intercambios entre la antropología mexicana y los antropólogos con base en Estados Unidos son significativos, lo cual ilustra claramente que estos intercambios internacionales han sido cruciales para el desarrollo

\section{Ángel Palerm and the Fieldwork: A Legacy that Prevails}

Gustavo Lins Ribeiro: Departamento de Antropología, Universidad de Brasilia, Brasilia, Brasil gustavor@unb.br

Robert V. Kemper: Southern Methodist University, Dallas, Texas, Estados Unidos 
de la disciplina durante mucho tiempo. Es importante recordar que Boas mismo fue consultor de Gamio, quien por lo general es reconocido como el "padre de la antropología mexicana" del siglo xx. Ambos estuvieron relacionados, a su vez, con otros dos denotados académicos: el francés Georges Engerrand y el alemán Eduard Seler, y establecieron en 1910 la Escuela Internacional de Arqueología y Antropología en la ciudad de México, aunque las actividades de esta escuela duraron poco debido a los efectos de la Revolución.

Aun así, como los cambios internacionales no ocurren en una sola dirección, debemos considerar de forma más detallada la influencia de los antropólogos y otros intelectuales mexicanos en la antropología estadounidense. Necesitamos saber, por ejemplo, cómo refleja el trabajo de Eric Wolf sus experiencias en México con sus colegas Ángel Palerm y Arturo Warman. Wolf compartía con ellos una orientación antropológica marxista y durante los años sesenta y setenta del siglo xx el mar-

xismo fue una perspectiva teórica extremadamente elaborada en Latinoamérica. En ese entonces, como consecuencia del McCartismo, era mucho más fácil encontrar interlocutores marxistas calificados en la academia mexicana y latinoamericana que en la estadounidense.

Pérez Lizaur nos recuerda la difícil pregunta: ¿cómo enseñamos investigación y metodología de campo? Y está en lo cierto cuando sugiere que cada profesor y estudiante aportan algo diferente a este tema, de modo que nuestras concepciones sobre etnografía suelen depender del lugar que ocupa la subjetividad personal en nuestras experiencias etnográficas. Como declara en la conclusión de su artículo, el contexto especial de trabajo en El Tajín sentó las bases de la escuela de campo de Palerm. En lo que se refiere a las relaciones con los estudiantes, mientras que la información referente a Boas y a Kroeber los muestra como maestros muy lejanos de los alumnos, tanto Kelly como Palerm aparecen como maestros cercanos a sus discípulos. La información disponible revela que la Escuela Nacional de
Antropología e Historia (ENAH) de los años cuarenta del siglo pasado y la UIA fueron espacios docentes en los que era posible que los maestros establecieran relaciones cercanas con los estudiantes.

La etnografía se sostiene tanto en los intercambios objetivos como en los intersubjetivos que ocurren durante el trabajo de campo y, como tal, la mejor forma de comprenderla es como una serie de encuentros comunicativos en los que los participantes ansían tener bajo control y, eventualmente, minimizar la ignorancia que comparten sobre situaciones de campo particulares. ${ }^{1}$ La noción de extrañamiento es crucial para este argumento. Se refiere a la conciencia de que tanto los investigadores como aquellos que son investigados sienten que viven/experimentan interacciones torpes, en particular porque los participantes en el encuentro etnográfico típicamente no reproducen sus encuentros comunicativos rutinarios ni sus actos de habla cotidianos. Mientras en el campo los antropólogos y las antropólogas están fuera de sus espacios cotidianos y deben monitorear sus nuevas relaciones, se exponen a situaciones donde su "conciencia práctica" — es decir, todas las cosas que los actores saben de forma tácita (Giddens, 1984) - es temporalmente incapaz de interpretar con precisión nuevos entornos y nuevos sujetos. Esta incapacidad obliga a los etnógrafos a reforzar su proceso perceptual y cognitivo en negociaciones con las otras personas, quienes a su vez ansían "domesticar" a esos extraños inquisitivos. La experiencia etnográfica queda conformada, por tanto, como una serie de encuentros en un proceso mutuo de negociación de ignorancia y ansiedad, cuya meta es producir una fusión de horizontes que vuelva a hacer predecible la vida diaria de los participantes. Cuando la fusión de horizontes es total y la gente comienza a preguntarte quiénes son ellos y por qué se comportan de cierta manera, la investigación está terminada. En dicho momento, los etnógrafos ${ }^{1}$ Sobre este argumento y los siguientes véase Ribeiro (1999
y 2012). 
pueden empezar a trabajar en un nuevo campo, adoptar una perspectiva longitudinal que involucre nuevas preguntas de investigación a resolver en el mismo lugar o combinar nuevos sitios con una base comparativa con el original (Kemper y Peterson, 2011).

Este enfoque hacia la experiencia etnográfica como un proceso de negociación de ignorancia es también parte constitutiva de la idea de que la etnografía es una experiencia solitaria y cambiar de ámbito de investigación o adoptar una perspectiva longitudinal son dos alternativas distintas para mantener nuestra conciencia antropológica alerta. De esta manera, el trabajo de campo crea una cierta tensión entre un tratamiento más individualista de la etnografía y uno más colectivista. De hecho, la centralidad que otorga la tradición de Palerm al trabajo de campo colectivo va, como señala Roger Magazine en su artículo, en contra de los modelos más individualizados que actualmente dominan la disciplina. Lo que Palerm aprendió de Kelly se volvió parte de la tradición continua de formación de campo de la UIA. Palerm aprendió también otras lecciones, como que el trabajo de campo debe aprenderse en el campo y no en las aulas, elemento fundamental del análisis sobre el programa de formación en trabajo de campo en la UIA que hace Magazine. La comparación de su experiencia personal en la Johns Hopkins University - que podría haberse replicado en muchas otras universidades estadounidenses - con la que vivió en la UIA habla por sí misma en tributo a la continuidad del énfasis de Palerm en la formación de campo.

El compromiso con el individualismo, por un lado, y la determinación de que estudiantes y profesores deben estar dispuestos a colaborar en el proyecto general, por otro, apuntan a la continuidad de esta tradición. En cierto sentido, este equilibrio entre individualismo y colectividad refleja un importante conjunto de valores en la historia cultural de México en el siglo xx. Podemos ver que si bien los individuos pueden reclamar propiedad intelectual sobre su material de campo, a su vez aceptan que pueden reclamar sólo el usufructo de lo que, en última instancia, es el patrimonio histórico de la gente con la que llevan a cabo sus estudios de campo. Esta manera de equilibrar los derechos individuales y colectivos en el contexto del entrenamiento para el trabajo de campo cuestiona algunos de los valores inherentes en desarrollos recientes del Estado neoliberal, en particular su énfasis en la producción científica para y por el usufructo del sector privado. Como antropólogos debemos preguntarnos: ¿qué utilidades produce nuestro trabajo de campo y a quién le pertenecen en realidad?

Magazine expone un punto importante cuando nos llama a "elevar nuestra conciencia sobre la manera en que los métodos de formación se ven influidos por factores sociales o culturales de los que a menudo no estamos conscientes en el entorno familiar y en apariencia culturalmente neutral de la academia”. Palerm y su generación realizaron trabajo de campo antes de que las críticas de los noventa del siglo pasado hicieran problemáticas las pretensiones de objetividad y realismo de los antropólogos. Voltear la mirada hacia Palerm y sus contemporáneos nos lleva a una generación que practicó la investigación de campo con otros intereses y otras convicciones en mente. Por ejemplo, para ellos la objetividad era un valor. Sus técnicas suponían que existía "algo allá afuera" que podía ser descrito objetivamente y de lo cual era posible encontrar patrones y reglas. En comparación con lo que ocurre hoy en día, los investigadores integrantes de esa generación estaban más interesados en lo que oían al hablar con sus sujetos de investigación, en lo que observaban y registraban en sus notas de campo que en la manera en que la experiencia etnográfica perturbaba sus egos.

$\mathrm{Al}$ recordarnos que las dinámicas culturales $-\mathrm{y}$ las políticas- pueden influir en cómo concebimos y practicamos la investigación en campo, Magazine abre un vasto universo comparativo. Mientras el estilo de investigación colectiva de Palerm y sus rituales de iniciación centrados en el campo son envidiables, también cuestionan el canon etnográfico, en particular el paradigma malinowskiano del etnógrafo 
solitario. Sean determinadas por ideologías individualistas o no, la soledad y la separación de "casa" tienen un papel estratégico en la etnografía. Una cosa es regresar a casa a encontrarse con la familia y con colegas investigadores y otra muy diferente que en el trabajo de campo "casa" signifique vivir exclusivamente con la gente que se está estudiando.

La comparación que hace Magazine de la situación en la UIA con su año como pasante en la Johns Hopkins nos hace preguntarnos a cuántos estudiantes se les hace tomar cursos de metodología y estrategias de investigación y análisis de datos. En la actualidad hay tal concentración de atención en la teoría que dichas metodologías y estrategias casi han sido olvidadas, a menos que se las recupere para criticarlas como pretensiones de objetividad. Ésta bien puede ser la razón de que los antropólogos encuentren tan difícil defender nuestras aportaciones particulares a la investigación académica, en especial a la etnografía. Parece que hoy cualquiera puede aseverar que hace etnografía.

¿Puede enseñarse el trabajo de campo como lo hizo Kelly con Palerm y sus compañeros a través de sus experiencias con los totonacos del Tajín? El método practicado en la UIA, en otros lugares en México, en España y en Estados Unidos - como muestran los artículos complementarios de Carlos Giménez Romero y Laura González y Víctor García - sugiere que puede enseñarse colectivamente y no sólo vivirse de manera individual. No olvidemos que aun durante estas experiencias colectivas los estudiantes también deben llevar a cabo proyectos individuales de investigación para entender la complejidad de la experiencia etnográfica.

Queda la pregunta: ¿por qué hay tan pocos proyectos exitosos de formación de campo en etnología mientras que ésta es la norma en la arqueología? Con certeza, el individualismo y el productivismo son parte de la respuesta, junto a las místicas autorales y malinowskianas. De manera adicional, ahora nos enfrentamos a un aumento en la burocratización de los protocolos de investigación - como lo requieren los comités de asuntos humanos de los campus universitarios-, a nuevas reglas de auditoría y contabilidad de los fondos universitarios y de las subvenciones de fundaciones y del Estado, y a una transformación sustancial de la ética de las relaciones entre investigadores y aquellos que estudiamos (Kemper y Peterson, 2001). En un entorno de circunstancias tan cambiantes es destacable que podamos rastrear el acercamiento colectivo al trabajo de campo desde el proyecto de Kelly en Veracruz a la "casa de campo" de Palerm en el Estado de México y hasta la "Casa Palerm" operada por Laura González en Dallas, Texas, y la casa de campo fundada por Juan Vicente Palerm en el sur de California, donde Víctor García recibió su entrenamiento inicial en trabajo de campo.

El trabajo de Giménez Romero muestra otras conexiones que participan en la construcción de intercambios entre antropólogos. Aquí vemos el papel de Juan Vicente Palerm, el hijo de Ángel, en la diseminación del enfoque de su padre por España y, después, por Estados Unidos. De hecho, cuando Juan Vicente pudo enseñar y conducir nuestro trabajo de campo en España, usó el Outline of Cultural Materials de los Human Relations Area Files - conocido como la Guía Murdock-, que fue traducido originalmente al español en la década de 1950 a través de las oficinas de la Unión Panamericana, donde trabajaba su padre en esa época. Parece especialmente apropiado que la Guía Murdock haya llegado al español por medio de la Unión Panamericana dado que Palerm recibió entrenamiento en su uso por parte de Kelly, quien lo impartió a todos sus estudiantes en el Proyecto Tajín. Más allá de esto, el artículo de Giménez Romero nos recuerda que la vida de un intelectual y académico como Ángel Palerm es representativa de toda una generación de colegas heroicos y carismáticos - para hablar en los términos weberianos que Roberto Cardoso de Oliveira usara alguna vez para referirse a la historia de la antropología brasileña-. Ángel Palerm no sólo era profesor, investigador y autor, también era un intelectual público, un hacedor de políticas y un constructor de instituciones. Debemos preguntarnos finalmente: ¿aún es posible 
crear este tipo de académico o las estructuras burocráticas y las fuerzas productivistas impiden el surgimiento de líderes así de versátiles y carismáticos?

González y García describen por su parte una experiencia en Texas que fue clave para cambiar la situación social de los jóvenes latinos. En pocas palabras, dan testimonio de cómo el "modelo de investigación" de Palerm puede transformarse en un modelo para la inclusión. Sus resultados positivos se basan en pocas pero poderosas características de la visión de Palerm: en primera instancia, una disminución, temporal y controlada, de las distancias jerárquicas entre profesores y estudiantes, que abre la puerta a prospectos para nuevas relaciones de confianza, sólidas y respetuosas; en segunda instancia, enfatizar la práctica colectiva puede convertirla en una metonimia de la comunidad en su totalidad y demostrar el poder de la imaginación y la acción colectivas para resolver problemas locales. La experiencia de García y González confirma claramente que el acercamiento colectivo de Palerm a la investigación de campo demuestra que en antropología, como en otros ámbitos, participación, cooperación y confianza son palabras clave. En general, en estas contribuciones observamos la emergencia de una red de personas que han llevado ideas que aprendieron de Palerm - y con Palerm - a nuevos espacios en México, España y Estados Unidos. A Kelly no le sorprendieron la carrera de Palerm y su legado, que hizo énfasis en la importancia constante de la experiencia de campo en la antropología, y a nosotros tampoco. Ya ha escrito Patricia Torres Mejía con gran precisión:
Dejó en México una escuela de antropología tan amplia que en la actualidad no hay instituto de enseñanza superior o de investigación en antropología social en el que no estén presentes exalumnos de Ángel Palerm (Torres, 1988: 123).

\section{BIBLIOGRAFÍA}

Giddens, Anthony, 1984, The Constitution of Society, Polity Press, Cambridge.

Kelly, Isabel y Ángel Palerm, 1952, The Tajín Totonac. Part I. History, Subsistence, Shelter, and Technology, Institute of Social Anthropology-The Smithsonian Institution (Publication 12), Washington, D. C.

Kemper, Robert V. y Anya Peterson Royce, 2001, "Cuestiones éticas para los antropólogos sociales en México: una perspectiva norteamericana a largo plazo", en Boletín del Colegio de Etnólogos y Antropólogos Sociales, núm. 4, Colegio de Etnólogos y Antropólogos Sociales, México, pp. 2-11.

(eds.), 2011, Crónicas culturales, Universidad Iberoamericana, Centro de Investigaciones y Estudios Superiores en Antropología Social, México.

Ribeiro, Gustavo Lins, 1999, "Descotidianizar. Extrañamiento y conciencia práctica, un ensayo sobre la perspectiva antropológica", en Maurício F. Boivin, Ana Rosato y Victória Arribas (eds.), Constructores de otredad, Editorial Universitaria de Buenos Aires, Buenos Aires.

2012, "From Local to Global Ethnographic Scenarios", en Alma Goetlieb (ed.), The Restless Anthropologist, University of Chicago Press, Chicago, pp. 35-48.

Torres Mejía, Patricia, 1988, “Ángel Palerm Vich”, en Lina Odena Güemes y Carlos García Mora (coords.), La antropología en México, panorama histórico, vol. 11: Los protagonistas (Nájera-Yurchenco), Instituto Nacional de Antropología e Historia, México, pp. 117-143. 